\title{
Effect of a Home-Based Exercise Program on Indices of Physical Function and Quality of Life in Elderly Maintenance Hemodialysis Patients
}

\author{
Jonathan Myers ${ }^{a, b}$ Khin Chan ${ }^{a, c}$ Yu Chen ${ }^{a}$ Yiming Lit ${ }^{c, d}$ Alessandro Patti ${ }^{\mathrm{e}}$ \\ Payam Massaband $^{\text {e }}$ B. Jenny Kiratlif Manju Tamurac, d Glenn M. Chertow ${ }^{d}$ \\ Ralph Rabkin ${ }^{c, d}$ \\ ${ }^{a}$ Cardiology Division, Veterans Affairs Palo Alto Health Care System, Palo Alto, CA, USA; ${ }^{b}$ Cardiology Division, \\ Stanford University, Stanford, CA, USA; ' Nephrology Section, Veterans Affairs Palo Alto Health Care System,

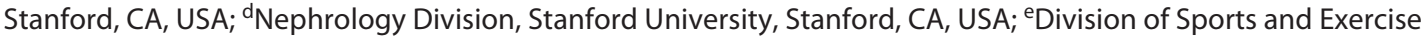

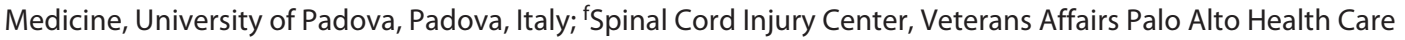 \\ System, Palo Alto, CA, USA
}

\begin{abstract}
Keywords
Home-based exercise - Cardiopulmonary exercise testing . Exercise training $\cdot$ Hemodialysis $\cdot$ Randomized clinical trial
\end{abstract}

\begin{abstract}
Background: Patients on maintenance hemodialysis (MHD) exhibit muscle wasting and impaired physical function which can be reversed with regular exercise, but accessibility to exercise programs for this unique population is lacking. We assessed the efficacy of a home-based exercise program on a broad range of indices of physical function, quality of life (QoL), and cognitive decline in patients with MHD. Design and Methods: Twenty-eight MHD patients, mean age $66 \pm 7$ years, were randomized to a 12-week home-based, case-managed aerobic and resistance exercise program or to usual care (13 exercise and 15 usual care). Comparisons were made for peak $\mathrm{VO}_{2}$, ventilatory inefficiency, 6-min walk test (6MWT), 1-min sit-to-stand (1STS), muscle strength, body composition, QoL, and cognitive measures. Results: Peak $\mathrm{VO}_{2}$ improved significantly in the exercise group $(p=$ 0.01 between groups); exercise time improved by 41 and
\end{abstract}

karger@karger.com www.karger.com/kbr

Karger $\stackrel{\text { ' }}{5}$

GOPEN ACCESS
(C) 2021 The Author(s)

Published by S. Karger AG, Basel

This is an Open Access article licensed under the Creative Commons Attribution-NonCommercial-4.0 International License (CC BY-NC) (http://www.karger.com/Services/OpenAccessLicense), applicable to the online version of the article only. Usage and distribution for commercial purposes requires written permission.
$36 \%$ at the ventilatory threshold and peak exercise, respectively ( $p<0.01$ between groups), but there were no differences in ventilatory efficiency. Trends for improvements in 6MWT and 1STS in the exercise group were observed, but no differences were observed in strength or body composition. Among measures of QoL, general health determined by the SF-36 improved in the exercise group, but there were no differences between groups in cognitive function. Conclusions: MHD patients improved exercise capacity and some indices of QoL following a 12-week home-based exercise program. Home-based exercise is feasible for patients undergoing MHD and may help to obviate accessibility barriers to regular exercise.

(c) 2021 The Author(s)

Published by S. Karger AG, Basel

\section{Introduction}

In CKD, muscle mass and physical function decline as renal failure progresses [1-3]. These processes are accelerated in elderly dialysis patients since both the uremic environment and aging cause loss of muscle mass and 


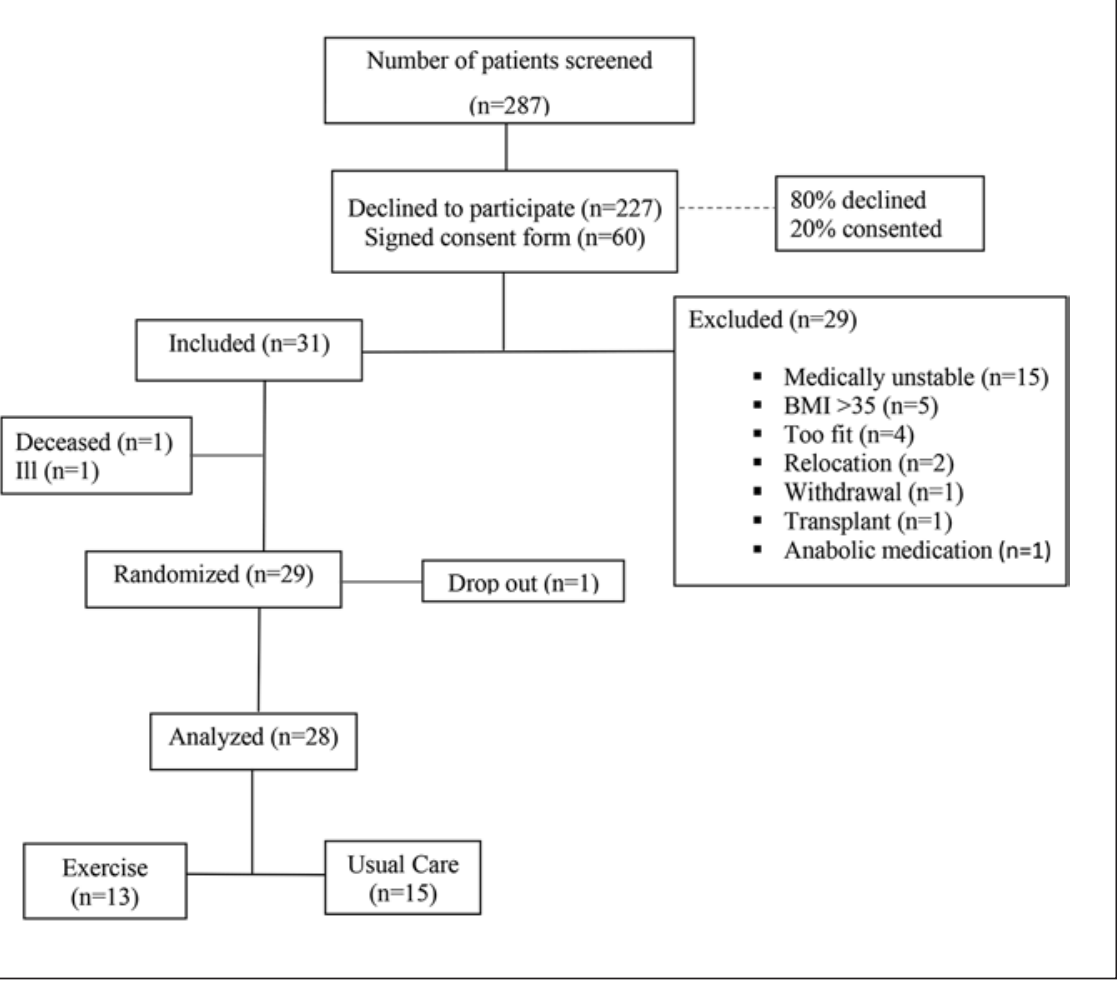

Fig. 1. Study recruitment flowchart.

function that together predispose these individuals to frailty. This inevitably leads to an increase in fall-related injuries, a decrease in quality of life (QoL), and an increase in morbidity and mortality $[4,5]$. The mortality rate among $\mathrm{CKD}$ patients on maintenance hemodialysis (MHD) increases by 2 -fold among those aged 66-74 and approximately 3 -fold in those aged 75-79 versus those $<65$ years $[6,7]$. Current recommendations to prevent and manage aging-related adverse events in MHD include adopting a regular exercise routine [8-10]. Several studies in patients with CKD have reported that both intensive and moderate aerobic training improve cardiovascular performance $[11,12]$. This is particularly important in CKD, given their high prevalence of cardiovascular disease that accounts for nearly half their deaths [13]. In addition, regular aerobic exercise can increase muscle fiber size in patients with CKD to an extent that is similar to that in age-matched reference subjects [14-17].

Despite recommendations for exercise-based therapy in patients with CKD, implementation of exercise programs as a standard treatment modality is limited. There are numerous barriers to participation in physical activity for persons with CKD that inhibit the adoption of a consistent exercise routine $[18,19]$, particularly those with end-stage renal disease who are undergoing MHD. These include lack of insurance reimbursement, lack of transportation, lack of accessible or affordable fitness facilities, and lack of appropriate equipment and knowledgeable staff. In addition, personal issues unique to MHD that hinder participation in physical activity include lack of knowledge regarding appropriate exercise, lack of awareness of its benefits, and lack of energy or motivation. A major gap exists between research findings on the benefits of exercise and the clinical implementation of rehabilitation as a treatment modality in MHD patients.

A need exists for low-cost exercise programs that are relatively easy to administer and adhere to and that will form part of routine end-stage renal disease care. Home programs provide one such option. With delivery of an exercise program that can be conducted at home on a personalized schedule, compliance to the program may be optimized [20,21]. Among patients with cardiovascular disease, home programs have been demonstrated to be as efficacious as traditional center-based programs in terms of physical function as well as reductions in hospitalizations and morbidity and mortality [22]. Moreover, adherence has been demonstrated to be similar, and costs are 
Table 1. Baseline demographic and clinical characteristics of the participants

\begin{tabular}{lcccc}
\hline & Total $(n=28)$ & EX $(n=13)$ & UC $(n=15)$ & $p$ value* \\
\hline Demographics & & & & 0.96 \\
Age, years & $66.3 \pm 6.9$ & $66.3 \pm 7.6$ & $66.2 \pm 6.7$ & 0.70 \\
BMI, kg/m ${ }^{2}$ & $28.7 \pm 4.0$ & $28.4 \pm 3.4$ & $29.0 \pm 4.6$ & 0.27 \\
Male, $n$ & 21 & 13 & 15 & 0.61 \\
Peak VO, $\mathrm{mL} / \mathrm{kg} / \mathrm{min}$ & $14.8 \pm 3.2$ & $14.5 \pm 3.3$ & $15.1 \pm 3.3$ & 0.01 \\
FVC, $\mathrm{L}$ & $2.51 \pm 0.95$ & $1.98 \pm 0.53$ & $2.95 \pm 1.0$ & 0.22 \\
FEV, $\mathrm{L}$ & $1.64 \pm 0.71$ & $1.44 \pm 0.59$ & $1.91 \pm 0.78$ & 0.69 \\
Kt/V & $2.04 \pm 0.37$ & $2.01 \pm 0.43$ & $2.07 \pm 0.34$ & 0.83 \\
BUN, mg/dL & $69.4 \pm 16.6$ & $68.7 \pm 18.5$ & $70.1 \pm 15.4$ & 0.001 \\
Creatine, mg/dL & $9.70 \pm 2.2$ & $11.1 \pm 2.2$ & $8.6 \pm 1.6$ & 1.0 \\
\hline Clinical history, $n$ [\%] & & & & $15[100]$ \\
Hypertension & $28[100]$ & $13[100]$ & $10[66.7]$ & 0.55 \\
Type II DM & $19[67.9]$ & $9[69]$ & $5[33.3]$ & 0.78 \\
CAD & $10[35.7]$ & $5[38.5]$ & $3[20]$ & 0.50 \\
Stroke & $6[21.4]$ & $3[23]$ & $3[20]$ & 0.35 \\
Liver disease & $4[14.3]$ & $1[7.7]$ & $3[20]$ & 0.75 \\
Cancer & $4[14.3]$ & $1[7.7]$ & $4.05 \pm 3.9$ & 0.89 \\
Duration of MHD, years & $4.14 \pm 3.9$ & $4.25 \pm 3.9$ & & \\
\hline
\end{tabular}

EX, exercise; UC, usual care; FVC, forced vital capacity; $\mathrm{FEV}_{1}$, forced expiratory volume, $1 \mathrm{~s}$; DM, diabetes mellitus; CAD, coronary artery disease; $\mathrm{MHD}$, maintenance hemodialysis; $\mathrm{BUN}$, blood urea nitrogen. ${ }^{*} p$ value between exercise and usual care groups.

lower for such programs [22-24]. We undertook the current randomized trial in order to assess the impact of a home-based exercise program on detailed health metrics including cardiopulmonary exercise test responses, pulmonary function, psychosocial health, strength, balance, and anthropometric measures in elderly end-stage renal disease patients undergoing MHD.

\section{Materials and Methods}

\section{Subjects}

Details of the study design and measurements have been published previously [25] (clinical trials \#NCT01990495). In brief, men and women aged $55-80$ years with impaired exercise capacity (peak $\mathrm{VO}_{2} \quad 10-20 \mathrm{~mL} / \mathrm{kg} / \mathrm{min}$ ) undergoing MHD for at least 3 months with an average $\mathrm{Kt} / \mathrm{V} \geq 1.2$ were eligible for the study. $\mathrm{Pa}$ tients with temporary vascular access, uncontrolled diabetes mellitus, active autoimmune disease, malignancy, severe obesity (BMI $>35$ ), alcoholism or other recreational drug use, unstable cardiac disease (abnormal exercise test, angina, uncontrolled arrhythmias, or myocardial infarction within 3 months), peripheral vascular disease (claudication with exercise), those who were currently active ( $>2 \mathrm{~h}$ /week of moderate intensity exercise), and those who had received anabolic, catabolic, or cytotoxic medications in the past 3 months were excluded from participation. Subjects were recruited from the Veterans Affairs Palo Alto Healthcare System (VAPAHCS), Stanford University Medical Center, and local Satel- lite Dialysis Inc. clinics within 30-40 miles of the VAPAHCS and through local nephrologists. The study was approved by the Stanford University Panel on Human Subjects (protocol \#27400), and all subjects gave written informed consent.

\section{Recruitment and Enrollment}

Figure 1 summarizes potential participants from recruitment to randomization. We approached 287 potential subjects; 228 (80\%) declined to participate. Sixty patients signed consent forms. Among the 60 who were interested in participating, 29 (48\%) were excluded, mostly for medical instability. Of the remaining 31 subjects, one died and one became ill for reasons unrelated to the study. We randomized the remaining 29 participants; there was 1 dropout, and 28 participants were included in the current analysis (21 males and 7 females). Table 1 provides demographic and clinical characteristics of the participants in each group. Thirteen subjects were randomized to the exercise intervention group and 15 to usual care; the mean age of the sample was $66.2 \pm 7.0$ years. Ethnicity of the sample was as follows: 9 Asian, 6 Hispanic, 6 Caucasian, 4 Pacific Islander, and 3 African American. Seventy percent of participants had type II diabetes, and all subjects had a history of hypertension. There were no differences between groups at baseline in terms of age, demographics, or clinical history, but forced vital capacity was higher in the usual care group. The mean peak $\mathrm{VO}_{2}(14.8 \pm 3.2 \mathrm{~mL} / \mathrm{kg} / \mathrm{min})$ of the sample represented $55 \%$ of the age-predicted value [26].

\section{Cardiopulmonary Exercise Testing}

Standardized medical examinations were performed prior to testing, and medications were continued as prescribed. Symp- 
tom-limited exercise testing was performed using an individualized ramp protocol. The protocol was individualized to fall within the recommended 8- to 12-min range as previously described [27]. Most subjects performed exercise testing on a treadmill; a cycle ergometer was used for subjects who required additional stability. The same modality was used for pre- and posttesting for a given subject. In the absence of clinical indications for stopping, the tests were continued until volitional fatigue, and the Borg [28] 6-20 perceived exertion scale was used to quantify effort. Exercise capacity in metabolic equivalents (METs) was estimated from peak treadmill speed and grade [29]. Cardiopulmonary exercise testing (CPET) responses were obtained using a CosMed Quark CPET metabolic system (CosMed Inc., Rome, Italy). Minute ventilation (VE), oxygen uptake $\left(\mathrm{VO}_{2}\right)$, carbon dioxide production $\left(\mathrm{VCO}_{2}\right)$, and other cardiopulmonary exercise test variables were acquired breath by breath and reported in 10 -s intervals using rolling $30-s$ averages. The ventilatory threshold was determined by 2 blinded reviewers using standardized methods [30]. $\mathrm{VE}$ and $\mathrm{VCO}_{2}$ responses throughout exercise were used to calculate the $\mathrm{VE} / \mathrm{VCO}_{2}$ slope via least squares linear regression $(y=m x+b, m=$ slope $)$ [31]. The oxygen uptake efficiency slope (OUES) was calculated using $\left(\mathrm{VO}_{2}[\mathrm{~L} / \mathrm{min}]=m\left[\log _{10} \mathrm{VE}\right]+b\right.$, where $m=$ OUES). Percentage age-predicted peak $\mathrm{VO}_{2}$ was expressed using both the FRIEND [26] and Wasserman et al. [32] equations.

Because chronotropic incompetence has been associated with CKD [33], we also determined heart rate reserve (HRRes), defined as (peak heart rate - resting heart rate]; heart rate reserve as a percentage of peak (HRRes \% peak) defined as (HRRes/peak heart rate $\times 100)$; and HRRes as a percentage of rest (HRRes $\%$ from rest) defined as (HRRes/resting heart rate $\times 100)$.

\section{Body Composition}

A whole-body dual X-ray absorptiometry scan was performed to assess total body lean mass and percent body fat. Either a CT or MRI was performed on the midthigh to determine thigh muscle mass and to calculate percentage of intramuscular fat.

Quality of Life

Participants completed a quality of life questionnaire (SF-36v2) [34] and kidney disease-specific quality of life survey (KDQOL) [35] to assess physical, psychological, and social areas of health. In addition, a battery of 5 cognitive tests was employed to assess cognitive domains including visuospatial scanning, psychomotor speed, executive function, attention, verbal learning, memory, and verbal cognitive flexibility [36].

\section{Other Functional Assessments}

Strength was determined using leg extension 1 repetition maximum for lower body strength and chest press 1 repetition maximum for upper body strength. Maximal isometric strength was determined using a hand grip dynamometer. A 6-min walk test was performed in a corridor in accordance with the American Thoracic Society Guidelines [37]. A 1-min sit-to-stand (1STS) test was performed to measure balance and muscle power; this included time to complete 5 repetitions and number of repetitions completed within $1 \mathrm{~min}$ [38]. Standard pulmonary function tests, including forced vital capacity (FVC) and forced expiratory volume in $1 \mathrm{~s}\left(\mathrm{FEV}_{1}\right)$, were performed.

Home-Based Exercise in Hemodialysis

\section{Exercise Intervention}

Participants randomized to the exercise group underwent a 12week individualized home-based exercise program. Following 1-3 hospital outpatient-based supervised sessions, the exercise programs were performed at home. Participants were given hand-held weights and Thera-bands in accordance with their capabilities and portable cycle ergometers for home use. Subjects were instructed to strictly adhere to their exercise prescriptions and encouraged to perform a combination of continuous aerobic activities and resistance exercise for a minimum of $45 \mathrm{~min}$ per day. Daily activity logs were used to record intensity and duration of activities along with steps and heart rate using a wearable device. Exercise intensity was targeted to achieve $70-80 \%$ of HR reserve and $12-14$ on the Borg [28] perceived exertion scale. Participants received a weekly follow-up phone call by a study coordinator to ensure stability and compliance and to modify the exercise prescription as appropriate. Subjects randomized to the usual care group received standard clinical care.

\section{Statistics}

Variables are presented as mean \pm SD. Demographic and clinical variables at baseline between groups were compared using unpaired $t$ tests for continuous variables and $\chi^{2}$ tests for categorical variables. Differences between groups before and after 12 weeks were compared using multivariate ANOVA, with group and test as factors. Post hoc tests were performed using the Bonferroni method.

\section{Results}

All 28 participants completed the baseline and 12week procedures. There were no adverse events in either group related to testing or training. During CPET, both groups achieved maximal exercise perceived exertion values $\approx 19$ and respiratory exchange ratios $\geq 1.0$, suggesting maximal efforts were generally achieved.

\section{Functional Tests, Body Composition, and Health Status}

Table 2 shows comparisons between groups for functional tests, strength, pulmonary function, and body composition. While the exercise group generally improved their performance on functional and strength evaluations and the usual care group was generally unchanged, the differences between groups were not significant. Body composition indices were not different between groups. Both $\mathrm{FEV}_{1}$ and $\mathrm{FVC}$ tended to improve in the exercise group after the training period (by 20 and $28 \% ; p=0.53$ and 0.07 between groups, respectively).

\section{Cardiopulmonary Exercise Testing}

CPET results at the ventilatory threshold and peak exercise are presented in Tables 3 and 4, respectively. At the ventilatory threshold, $\mathrm{VO}_{2}$ increased slightly in the exercise group and was reduced among usual care subjects, 
Table 2. Functional, strength, pulmonary function, and body composition measures at baseline and 12 weeks

\begin{tabular}{|c|c|c|c|c|c|}
\hline & \multicolumn{2}{|c|}{ Usual care $(n=15)$} & \multicolumn{2}{|c|}{ Exercise $(n=13)$} & \multirow[t]{2}{*}{$p$ value $^{\ddagger}$} \\
\hline & baseline & 12 weeks & baseline & 12 weeks & \\
\hline \multicolumn{6}{|l|}{ Functional tests } \\
\hline 1STS (repetition, $n$ ) & $17.8 \pm 8.1$ & $18.2 \pm 7.5$ & $19.0 \pm 8.7$ & $23.8 \pm 6.8$ & 0.30 \\
\hline$\%$ predicted value, 1 STS & $55.5 \pm 18.2$ & $53.2 \pm 22.4$ & $54.6 \pm 25.6$ & $68.9 \pm 23.7$ & 0.18 \\
\hline STS duration 5 repetitions, $\mathrm{s}$ & $15.4 \pm 5.4$ & $16.9 \pm 10.1$ & $14.2 \pm 3.9$ & $12.4 \pm 4.4$ & 0.37 \\
\hline 6MWT, m & $313.2 \pm 64.8$ & $322.9 \pm 51.6$ & $333.2 \pm 79.6$ & $355.8 \pm 73.0$ & 0.72 \\
\hline$\%$ predicted value, $6 \mathrm{MWT}$ & $65.8 \pm 13.3$ & $67.3 \pm 11.4$ & $71.8 \pm 15.6$ & $76.7 \pm 13.7$ & 0.63 \\
\hline \multicolumn{6}{|l|}{ Strength } \\
\hline Hand grip & $53.1 \pm 16.4$ & $48.0 \pm 17.7$ & $54.2 \pm 15.4$ & $54.2 \pm 14.3$ & 0.54 \\
\hline$\%$ predicted value, hand grip & $68.3 \pm 15.6$ & $61.4 \pm 17.6$ & $68.0 \pm 18.3$ & $68.8 \pm 19.4$ & 0.42 \\
\hline Upper body strength, lbs & $59.3 \pm 30.8$ & $59.3 \pm 30.6$ & $69.3 \pm 27.6$ & $74.4 \pm 29.5$ & 0.75 \\
\hline Lower body strength, lbs & $70.0 \pm 25.8$ & $71.1 \pm 26.1$ & $71.4 \pm 22.5$ & $82.7 \pm 27.4$ & 0.46 \\
\hline \multicolumn{6}{|l|}{ Pulmonary function } \\
\hline FVC & $2.96 \pm 1.0$ & $2.60 \pm 0.83$ & $1.98 \pm 0.53$ & $2.54 \pm 0.74$ & 0.07 \\
\hline $\mathrm{FEV}_{1}$ & $1.82 \pm 0.78$ & $1.87 \pm 0.71$ & $1.44 \pm 0.59$ & $1.73 \pm 0.46$ & 0.53 \\
\hline \multicolumn{6}{|l|}{ Body composition } \\
\hline Total leg mass, kg & $24.3 \pm 4.4$ & $24.0 \pm 4.5$ & $22.6 \pm 3.8$ & $22.3 \pm 4.1$ & 0.98 \\
\hline Total body mass, kg & $80.6 \pm 14.0$ & $79.5 \pm 14.4$ & $79.2 \pm 14.6$ & $77.3 \pm 16.2$ & 0.92 \\
\hline Total body fat, $\%$ & $37.0 \pm 6.6$ & $37.7 \pm 6.7$ & $35.0 \pm 7.1$ & $34.1 \pm 8.4$ & 0.67 \\
\hline$\%$ predicted value, body fat & $133.1 \pm 18.3$ & $135.0 \pm 17.3$ & $133.3 \pm 24.9$ & $130.2 \pm 29.0$ & 0.69 \\
\hline
\end{tabular}

6MWT, 6-min walk test; 1STS, 1-min sit-to-stand test; FVC, forced vital capacity; $\mathrm{FEV}_{1}$, forced expiratory volume, $1 \mathrm{~s} .{ }^{\ddagger} p$ value for interaction between groups.

Table 3. Cardiopulmonary exercise test responses at the ventilatory threshold

\begin{tabular}{|c|c|c|c|c|c|}
\hline & \multicolumn{2}{|l|}{ Usual care } & \multicolumn{2}{|l|}{ Exercise } & \multirow[t]{2}{*}{$p$ value } \\
\hline & baseline & 12 weeks & baseline & 12 weeks & \\
\hline $\mathrm{VO}_{2}, \mathrm{~mL} / \mathrm{Kg} / \mathrm{min}$ & $10.8 \pm 2.9$ & $10.5 \pm 2.5$ & $10.7 \pm 3.0$ & $11.8 \pm 2.8$ & 0.12 \\
\hline $\mathrm{VO}_{2}, \mathrm{~mL} / \mathrm{min}$ & $875.5 \pm 296.7$ & $849.9 \pm 250.3$ & $817.8 \pm 181.7$ & $920.4 \pm 262.4$ & 0.09 \\
\hline $\mathrm{VCO}_{2}, \mathrm{~mL} / \mathrm{min}$ & $730.8 \pm 268.8$ & $656.7 \pm 157.1$ & $676.8 \pm 205.6$ & $779.2 \pm 274.1$ & $<0.05$ \\
\hline $\mathrm{HR}$, beats/min & $77.7 \pm 12.5$ & $80.7 \pm 13.2$ & $92.0 \pm 12.4$ & $87.1 \pm 13.2$ & 0.07 \\
\hline $\mathrm{HR}, \%$ predicted & $50.3 \pm 8.4$ & $52.4 \pm 9.3$ & $59.9 \pm 8.7$ & $56.9 \pm 9.3$ & 0.07 \\
\hline $\mathrm{VE}, \mathrm{L} / \mathrm{min}$ & $24.3 \pm 8.7$ & $22.5 \pm 6.2$ & $23.0 \pm 7.6$ & $27.0 \pm 10.6$ & 0.02 \\
\hline RER & $0.84 \pm 0.09$ & $0.79 \pm 0.07$ & $0.82 \pm 0.07$ & $0.84 \pm 0.09$ & 0.01 \\
\hline Time to VT, s & $200.9 \pm 109.1$ & $179.1 \pm 68.5^{*}$ & $238.0 \pm 107.0$ & $334.7 \pm 112.2^{*}$ & $<0.01$ \\
\hline Measured METs & $3.1 \pm 0.8$ & $3.0 \pm 0.7$ & $3.0 \pm 0.9$ & $3.3 \pm 0.8$ & 0.20 \\
\hline Estimated METs & $3.0 \pm 0.8$ & $2.9 \pm 0.7$ & $3.1 \pm 0.9$ & $3.6 \pm 1.1^{*}$ & 0.04 \\
\hline $\mathrm{RPE}$ & $12.4 \pm 3.5$ & $10.9 \pm 2.5$ & $11.5 \pm 3.0$ & $11.3 \pm 2.5$ & 0.32 \\
\hline
\end{tabular}

$\mathrm{HR}$, heart rate; $\mathrm{VCO}_{2}$, carbon dioxide production; VE, minute ventilation; VT, ventilatory threshold; RER, respiratory exchange ratio; METs, metabolic equivalents; RPE, rating of perceived exertion. ${ }^{\ddagger} p$ value for interaction between groups. $* p<0.05$ within group.

but the interaction between groups was not significant $(p=0.12)$. Exercise time, minute ventilation, $\mathrm{VCO}_{2}$, and estimated METs were significantly higher in the exercise group versus usual care subjects at the ventilatory threshold. At peak exercise, $\mathrm{VO}_{2}$ improved in the exercise group
( $p=0.01$ between groups), and similar improvements were observed for estimated METs, exercise time, ventilation, and peak METs expressed as an age-predicted value. No differences between groups were observed for changes in ventilatory inefficiency ( $\mathrm{VE} / \mathrm{VCO}_{2}$ slope and OUES). 
Table 4. Cardiopulmonary exercise test responses at peak exercise

\begin{tabular}{|c|c|c|c|c|c|}
\hline & \multicolumn{2}{|l|}{ Usual care } & \multicolumn{2}{|l|}{ Exercise } & \multirow[t]{2}{*}{$p$ value $^{ \pm}$} \\
\hline & baseline & 12 weeks & baseline & 12 weeks & \\
\hline $\mathrm{VO}_{2}, \mathrm{~mL} / \mathrm{Kg} / \mathrm{min}$ & $15.1 \pm 3.3$ & $14.8 \pm 3.8$ & $14.5 \pm 3.3$ & $16.2 \pm 3.6^{* *}$ & 0.01 \\
\hline $\mathrm{VO}_{2}, \mathrm{~mL} / \mathrm{min}$ & $1,224.1 \pm 338.2$ & $1,197.5 \pm 352.4$ & $1,134.8 \pm 228.6$ & $1,270.7 \pm 287.1^{* *}$ & 0.02 \\
\hline $\mathrm{VO}_{2} \%$ Wasserman & $65.3 \pm 17.8$ & $62.7 \pm 16.2$ & $55.6 \pm 16.5$ & $61.3 \pm 14.9$ & 0.10 \\
\hline $\mathrm{VO}_{2} \%$ FRIEND & $59.6 \pm 15.2$ & $57.9 \pm 14.3$ & $51.2 \pm 12.5$ & $56.6 \pm 13.8$ & 0.35 \\
\hline $\mathrm{VCO}_{2}$ peak, $\mathrm{mL} / \mathrm{min}$ & $1,273.5 \pm 396.2$ & $1,195.4 \pm 374.1$ & $1,185.1 \pm 340.8$ & $1,348.0 \pm 316.1^{* *}$ & $<0.01$ \\
\hline METs & $4.3 \pm 0.9$ & $4.2 \pm 1.1$ & $4.1 \pm 0.9$ & $4.6 \pm 1.0^{* *}$ & 0.02 \\
\hline$\%$ age pred METs & $60.0 \pm 22.8$ & $54.8 \pm 23.5$ & $59.8 \pm 28.5$ & $68.5 \pm 21.8$ & 0.02 \\
\hline $\mathrm{VE}, \mathrm{L} / \mathrm{min}$ & $44.4 \pm 13.4$ & $41.1 \pm 12.7$ & $42.3 \pm 14.7$ & $49.7 \pm 14.8^{* *}$ & $<0.001$ \\
\hline $\mathrm{BF}$, breaths/min & $29.7 \pm 7.7$ & $28.9 \pm 7.2$ & $35.9 \pm 6.7$ & $36.5 \pm 5.8$ & 0.31 \\
\hline $\mathrm{O}_{2}$ pulse & $13.2 \pm 3.9$ & $13.3 \pm 4.2$ & $10.8 \pm 1.6$ & $11.9 \pm 2.0$ & 0.57 \\
\hline RER & $1.04 \pm 0.09$ & $1.00 \pm 0.08$ & $1.03 \pm 0.13$ & $1.06 \pm 0.11$ & 0.07 \\
\hline Exercise time, s & $466.1 \pm 165.4$ & $443.7 \pm 162.7^{*}$ & $504.9 \pm 185.1$ & $688.5 \pm 210.4^{* *}$ & $<0.001$ \\
\hline Estimated METs & $4.5 \pm 1.5$ & $4.4 \pm 1.8$ & $4.8 \pm 2.0$ & $5.5 \pm 1.8^{* *}$ & 0.02 \\
\hline RPE (Borg) & $18.7 \pm 1.0$ & $19.1 \pm 1.1$ & $18.8 \pm 1.3$ & $19.2 \pm 1.1$ & 0.99 \\
\hline $\mathrm{VE} / \mathrm{VCO}_{2}$ slope & $33.7 \pm 7.7$ & $33.4 \pm 6.5$ & $35.3 \pm 7.5$ & $36.3 \pm 7.1$ & 0.51 \\
\hline OUES & $1.52 \pm 0.50$ & $1.50 \pm 0.46$ & $1.39 \pm 26$ & $1.48 \pm 0.46$ & 0.63 \\
\hline
\end{tabular}

VE, minute ventilation; RER, respiratory exchange ratio; RPE, rating of perceived exertion; METs, metabolic equivalents; \% age pred METS, percentage age-predicted $\mathrm{MET}$; $\mathrm{VO}_{2} \%$ Wasserman, percentage age-predicted peak $\mathrm{VO}_{2}$ achieved using the Wasserman equation; $\mathrm{VO}_{2} \%$ FRIEND, age-predicted peak $\mathrm{VO}_{2}$ achieved using the FRIEND equation; OUES, oxygen uptake efficiency slope. ${ }^{\ddagger} p$ value for interaction between groups. ${ }^{*} p<0.05$ within group. ${ }^{* *} p<0.001$ within group.

Table 5. Heart rate parameters during exercise and recovery

\begin{tabular}{|c|c|c|c|c|c|}
\hline \multirow[t]{2}{*}{ Parameter } & \multicolumn{2}{|l|}{ Usual care } & \multicolumn{2}{|l|}{ Exercise } & \multirow[t]{2}{*}{$p$ value $^{\ddagger}$} \\
\hline & baseline & 12 weeks & baseline & 12 weeks & \\
\hline Resting HR & $65.0 \pm 8.8$ & $69.3 \pm 10.0$ & $73.3 \pm 7.1$ & $69.4 \pm 7.9$ & 0.08 \\
\hline Peak HR & $93.6 \pm 13.2$ & $96.9 \pm 14.6$ & $107.2 \pm 18.9$ & $108.2 \pm 19.4$ & 0.58 \\
\hline Peak HR, \% predicted & $61.0 \pm 9.0$ & $63.4 \pm 10.4$ & $70.0 \pm 13.4$ & $70.8 \pm 13.5$ & 0.58 \\
\hline HRRes, beats & $28.6 \pm 11.7$ & $27.6 \pm 12.4$ & $33.9 \pm 17.2$ & $38.8 \pm 18.5$ & 0.11 \\
\hline HRRes, \% peak & $29.8 \pm 9.7$ & $27.8 \pm 10.0$ & $30.1 \pm 11.1$ & $34.1 \pm 12.6$ & $<0.05$ \\
\hline HRRes, \% from rest & $45.1 \pm 20.2$ & $41.1 \pm 20.3$ & $46.6 \pm 23.8$ & $56.6 \pm 28.8$ & 0.02 \\
\hline HR 5 min & $69.9 \pm 8.1$ & $74.2 \pm 10.4$ & $84.1 \pm 9.6$ & $80.0 \pm 10.4$ & 0.11 \\
\hline HR recovery $1 \mathrm{~min}$ & $7.1 \pm 10.9$ & $10.0 \pm 10.1$ & $10.5 \pm 8.7$ & $12.3 \pm 7.1$ & 0.83 \\
\hline HR recovery $2 \mathrm{~min}$ & $15.3 \pm 11.2$ & $17.7 \pm 11.1$ & $14.9 \pm 9.1$ & $20.1 \pm 9.8$ & 0.62 \\
\hline HR recovery $5 \mathrm{~min}$ & $23.7 \pm 11.2$ & $22.7 \pm 9.3$ & $23.1 \pm 11.8$ & $34.3 \pm 20.7^{* *}$ & 0.10 \\
\hline
\end{tabular}

HR, heart rate; HRRes, heart rate reserve; HRRes (\% peak), heart rate reserve as a percentage of peak; HRRes (\% from rest), heart rate reserve as a percentage of rest; HR $5 \mathrm{~min}$, heart rate at a matched 5-min work rate. ${ }^{\ddagger} p$ value reflects main effect between groups. ${ }^{* *} p<0.001$ within group (LSD).

\section{Chronotropic Responses to Exercise}

Heart rate parameters during exercise and recovery are shown in Table 5. Both groups had chronotropic incompetence, achieving between 60 and $70 \%$ of their agepredicted maximal heart rates. The chronotropic re- sponse improved in the exercise group; heart rate reserve was greater expressed as either HRRes (\% peak) or HRRes ( $\%$ from rest) ( $p<0.05$ between groups). Heart rate recovery at $5 \mathrm{~min}$ was higher in the exercise group after the training period ( $p<0.001$ within group). 


\section{QoL and Cognition}

Trends for improvements in each of the KDQOL scores in the exercise group were observed, and exercise participants demonstrated within-group differences for symptoms and effects, but there were no between-group differences. The exercise group tended to improve each of the domains of the SF-36 (in the order of 20-30\%), but only general health improved significantly in the exercise group relative to usual care $(p=0.02)$. No differences were observed in measures of cognition between groups.

\section{Discussion}

In recent decades, the health benefits of regular physical activity have been extended beyond treatment of cardiovascular disease to include a broad spectrum of chronic conditions, including those related to pulmonary disease, diabetes, neurologic conditions, cognitive decline, arthritis, osteoporosis, musculoskeletal disorders, and kidney disease [39-42]. In fact, the recently published US Health and Human Services (HHS) Guideline Advisory Committee Report on Physical Activity [42] outlines $>20$ chronic conditions for which regular physical activity is known to have beneficial effects. However, beyond the confines of a clinical research trial, patients with CKD rarely receive the benefits of regular exercise, particularly those on MHD $[19,43]$. This is due to the combination of a lack of appreciation for the benefits of exercise by the medical community, lack of insurance reimbursement, and lack of accessibility to fitness facilities due in part to reduced mobility and difficulties with transportation. While intradialytic exercise has been proposed as one solution [44], its application has been limited because it requires additional effort from clinical staff and is not reimbursable. Thus, despite its potential benefits, systematic integration of physical activity into routine clinical practice among patients with CKD is lacking.

The home-based, case-managed approach employed in the current study was designed to overcome some of these barriers. We observed significant improvements in peak $\mathrm{VO}_{2}$, exercise time, and other markers of the training response including a delay in the ventilatory threshold. While these changes were relatively modest, they are typical of other studies in CKD [45] and have a potentially important impact on health outcomes. A growing number of studies have reported that, much like conventional cardiac rehabilitation programs, exercise programs in patients with CKD are associated with better long-term outcomes, including morbidity and mortality [46, 47].
Peak $\mathrm{VO}_{2}$ powerfully predicts survival in CKD [48], and a 1-MET increase in exercise capacity, similar to that observed in the current study, has been associated with 10$25 \%$ reductions in mortality broadly across clinical populations [40, 41]. Greenwood et al. [46] recently reported that among $757 \mathrm{CKD}$ patients who responded favorably to an exercise program (defined as a $>50$ - $\mathrm{m}$ improvement in a shuttle walk test), there was a $40 \%$ lower risk of composite adverse events over 3 years. Torino et al. [49] observed that an increase in $6 \mathrm{MWT}$ performance of just 20 $\mathrm{m}$ (similar to the current study) was associated with a $6 \%$ reduction in risk for the composite endpoint of cardiovascular events, hospitalizations, and death in MHD patients. Among $>900$ patients with CKD followed for a mean of 7 years in the National Health and Nutrition Examination Survey, inactive subjects had a 56\% higher incidence of mortality compared to subjects who met the minimal HHS guidelines for physical activity [50]. We recently reported that veterans with comparatively low cardiorespiratory fitness ( $<5$ METs) had a markedly higher risk of developing CKD over 11 years [51]. Collectively, these studies underscore the importance of incorporating physical activity into the routine management of patients with CKD.

We did not observe differences in strength or body composition (Table 2). Previous trials that have focused on supervised resistance training in patients with CKD have generally reported improvements in strength, although some studies have reported no change $[52,53]$. Hiraki et al. [21] reported modest improvements in hand grip and knee extension strength in predialysis CKD subjects after 1 year of home-based training. Conversely, Bae et al. [54] reported no differences after 12 weeks of supervised training in muscle mass, body fat mass, fat percentage, BMI, and knee extension peak torque and flexion in a group of MHD patients, findings consistent with ours. In a recent meta-analysis on home-based exercise in the elderly by Thiebaud et al. [55], studies with greater supervision had more significant gains in strength when compared to unsupervised subjects, but these gains were generally small. In a meta-analysis that included 445 subjects with CKD, Pei et al. [56] reported that the 1STS score (a surrogate for lower body strength) was not altered by aerobic training, exercise intensity or length of the intervention. These studies and the current results suggest that the type of exercise therapy that would result in gains in strength or muscle mass may require greater supervision than is generally possible from home-based exercise.

MHD patients have impaired pulmonary function that contributes to functional limitations and mortality [57- 
59]. We recently observed that $\mathrm{FEV}_{1}$ was closely associated with indices of physical function in patients on MHD, and in a multivariate model, $\mathrm{FEV}_{1}$ was one of the 3 significant predictors of peak $\mathrm{VO}_{2}$ [57]. Potential mechanisms that may explain impaired respiratory function in patients undergoing MHD include not only reduced respiratory muscle strength but also volume overload causing lung congestion and chronic inflammation underlying telomere shortening, which has been shown to lead to senescence of lung alveolar and endothelial cells $[60,61]$. Regular exercise has been shown to reduce the decline in pulmonary function in CKD $[21,59]$; in particular, studies designed specifically to strengthen the respiratory muscles have reported improved respiratory muscle strength and pulmonary function [59, 62-64]. Pomidori et al. [65] reported improvements in respiratory muscle strength after a 6-month home walking program in MHD subjects, but no changes in $\mathrm{FVC}$ or $\mathrm{FEV}_{1}$. We observed a $28 \%$ improvement in FVC in the exercise group, a change with borderline significance ( $p=0.07$ between groups), and a change in $\mathrm{FEV}_{1}(20 \%)$ that was larger than several previous studies with larger numbers in which these differences were significant $[59,63]$. These mixed findings suggest the need for additional controlled trials to clarify the impact and type of training on pulmonary performance in CKD.

Patients with CKD are known to have chronotropic incompetence [66], and uremia appears to contribute to autonomic dysfunction [66, 67]. We therefore explored the impact of exercise training on heart rate behavior during exercise and recovery (Table 5). Notably, all subjects in the current study exhibited chronotropic incompetence, even when defined considering the presence of beta blockade [68] (75\% of our subjects were on $\beta$-blockers). Heart rate reserve, a reflection of chronotropic incompetence, significantly improved after training when expressed both as a percentage of peak and a percentage change from rest. It is also notable that nearly all of our subjects had impaired heart rate recovery, defined by either the commonly used threshold of $<12$ beats at 1 -min postexercise [68] or 22 beats at 2 -min postexercise that we have previously reported to be an optimal threshold for all-cause mortality in veteran subjects [69]. The modest improvements in both the chronotropic response to exercise and recovery from exercise suggest the potential for exercise training to improve autonomic function reflected by baroreflex insensitivity, reduced parasympathetic drive, or both. These factors are strongly associated with mortality in a broad spectrum of chronic disease populations [69] and suggest additional support for exercise therapy in CKD.

Home-Based Exercise in Hemodialysis
Reduced physical function in CKD is associated with poor health-related quality of life (HRQL), and strategies to improve HRQL were recently identified as important research priorities for patients with CKD and their caregivers $[70,71]$. While there is evidence that exercise programs improve HRQL in CKD, this has not been a consistent finding [72]. We employed the widely used SF-36 [34] and kidney disease-specific KDQOL [35] to assess physical and psychosocial areas of health. We observed general trends for improvement among exercise participants in the various domains of the SF-36, particularly physical functioning, role physical and role emotional, and a significant change in general health $(p=0.02)$, along with several within-group differences after exercise training. Similarly, each of the 5 domains of the KDQOL tended to improve following the exercise intervention although there were no significant interactions between groups. This is consistent with results from the recently completed Exercise Introduction to Enhance Performance in Dialysis (EXITE) trial [73], a large, randomized, multicenter trial to test whether a simple, personalized 6-month home-walking program improved functional status among MHD patients. Only 2 items on the KDQOL$\mathrm{SF}$, cognitive function and quality of social interaction, showed a statistically significant improvement in the exercise group relative to usual care, while the other $17 \mathrm{com}$ ponents of QoL did not differ. In a meta-analysis of 21 studies by Barcellos et al. [8], only 5 of 21 studies showed an improvement in the physical component score of the SF-36 following exercise training with a mean change of $\approx 10 \%$. While we did not find a significant change in the physical component score of the SF-36 in the current study, it is notable that it improved by $43 \%$ in the exercise group.

Finally, we did not observe a significant effect of training on cognitive function. A growing number of studies have demonstrated that patients with CKD commonly have some degree of cognitive impairment and that kidney dysfunction is associated with a more rapid decline in mental function than that in age-matched peers [74-76]. Previous studies have also demonstrated that regular exercise generally has a favorable impact on cognitive function in patients with CKD [77]. Mechanisms suggested for these favorable effects of exercise on cognition include improved cerebral blood flow, increased brain volume in the prefrontal cortex and hippocampus, higher brain-derived neurotrophic factor, increases in angiogenesis, neurogenesis, and synaptogenesis, and reductions in inflammatory markers resulting in improved brain plasticity and executive function $[76,77]$. Many of these programs 
involved longer interventions than the 3 months in the current study and some, particularly those among MHD subjects, involved a combination of cognitive training and exercise.

\section{Limitations}

Our study lacked sufficient numbers to detect significant differences in many of the functional and QoL indices assessed. Nevertheless, the analysis was comprehensive; in addition to exercise capacity, we assessed a broad spectrum of physical function indices including strength, body composition, HRQL, and cognition. The exercise intervention was relatively short in duration, and a longer intervention may be required to elicit more complete changes in physical, psychosocial, or cognitive function. The home-based approach may have elicited too moderate an exercise stimulus, although other studies have observed adaptations that were similar to the current study using home-based or supervised programs, at least in terms of fitness [78]. Finally, there were a relatively small number of subjects enrolled relative to the number screened (Fig. 1); thus, the sample may not be representative of the larger hemodialysis population. The most common reason for declining to participate was lack of motivation to commit to the study.

\section{Conclusions}

A 12-week home-based exercise program resulted in modest improvements in physical function, exercise capacity, chronotropic responses to exercise, pulmonary function, and HRQL. A higher intensity of exercise, longer duration, or larger sample size may be required to more definitively demonstrate the benefits of homebased exercise in MHD. Nevertheless, these findings support the concept that home-based programs that include case management offer an alternative for the large proportion of MHD patients who are unable to participate in traditional supervised programs or do not have access to exercise facilities.

\section{Statement of Ethics}

This study was approved by the Stanford University Panel on Human Subjects (protocol \#27400), and all subjects gave written informed consent. The study was conducted in accordance with the World Medical Association Declaration of Helsinki.

\section{Conflict of Interest Statement}

There are no conflicts of interest to declare.

\section{Funding Sources}

This study was funded by the Department of Veterans Affairs, Rehabilitation Research and Development, grant \#RX000915$01 \mathrm{~A} 1$.

\section{Author Contributions}

J.M. and R.R. acquired funding for the study, performed data analysis, and drafted the manuscript. K.H., Y.C., Y.L., P.M., R.R., and J.K. acquired data, provided technical support, and provided input on the draft of the manuscript. All authors read and approved the final manuscript.

\section{References}

1 Cheng XS, Lentine KL, Koraishy FM, Myers J, Tan JC. Implications of frailty for peritransplant outcomes in kidney transplant recipients. Curr Transplant Rep. 2019;6(1):16-25.

2 Musso CG, Jauregui JR, Macías Núñez JF. Frailty phenotype and chronic kidney disease: a review of the literature. Int Urol Nephrol. 2015;47(11):1801-7.

3 Zhou Y, Hellberg M, Svensson P, Höglund P, Clyne N. Sarcopenia and relationships between muscle mass, measured glomerular filtration rate and physical function in patients with chronic kidney disease stages 3-5. Nephrol Dial Transplant. 2018;33(2):342-8.

4 Abdel-Rahman EM, Turgut F, Turkmen K, Balogun RA. Falls in elderly hemodialysis patients. QJM. 2011;104(10):829-38.
5 Anand S, Kurella Tamura M, Chertow GM. The elderly patients on hemodialysis. Minerva Urol Nefrol. 2010;62(1):87-101.

6 Collins AJ, Foley RN, Herzog C, Chavers BM, Gilbertson D, Ishani A, et al. Excerpts from the US renal data system 2009 annual data report. Am J Kidney Dis. 2010;55(1 Suppl 1): S1-7. A426-427, 2009.

7 Stevens LA, Viswanathan G, Weiner DE. Chronic kidney disease and end-stage renal disease in the elderly population: current prevalence, future projections, and clinical significance. Adv Chronic Kidney Dis. 2010; 17(4):293-301.
8 Barcellos FC, Santos IS, Umpierre D, Bohlke M, Hallal PC. Effects of exercise in the whole spectrum of chronic kidney disease: a systematic review. Clin Kidney J. 2015 Dec;8(6):753-65.

9 McKenna CF, Salvador AF, Hendriks FK, Harris APY, van Loon LJC, Burd NA. Exercising to offset muscle mass loss in hemodialysis patients: the disconnect between intention and intervention. Semin Dial. 2019;32(4): 379-85.

10 The global renal exercise group [G-REX]. Available from: http://grexercise.kch.illinois. edu/mission. Accessed 2020 Jul 20.

11 Graham-Brown MPM, Jardine MJ, Burton JO. Cardiovascular adaptations associated with exercise in patients on hemodialysis. Semin Dial. 2019;32:361-7. 
12 Bronas UG. Exercise training and reduction of cardiovascular disease risk factors in patients with chronic kidney disease. Adv Chronic Kidney Dis. 2009;16(6):449-58.

13 United States renal data system. 2019. Available from: https://usrds.org/reference.aspx. Accessed 2020 Jul 7.

14 Chen Y, Sood S, McIntire K, Roth R, Rabkin R. Leucine-stimulated mTOR signaling is partly attenuated in skeletal muscle of chronically uremic rats. Am J Physiol Endocrinol Metab. 2011 Jul 26;301(5):E873.

15 Roshanravan B, Gamboa J, Wilund K. Exercise and CKD: skeletal muscle dysfunction and practical application of exercise to prevent and treat physical impairments in CKD. Am J Kidney Dis. 2017 Jun;69(6):837-52.

16 Johansen KL, Painter PL, Sakkas GK, Gordon P, Doyle J, Shubert T. Effects of resistance exercise training and nandrolone decanoate on body composition and muscle function among patients who receive hemodialysis: a randomized, controlled trial. J Am Soc Nephrol. 2006;17(8):2307-14.

17 Kouidi E, Albani M, Natsis K, Megalopoulos A, Gigis P, Guiba-Tziampiri O, et al. The effects of exercise training on muscle atrophy in haemodialysis patients. Nephrol Dial Transplant. 1998;13(3):685-99.

18 Clarke AL, Jhamb M, Bennett PN. Barriers and facilitators for engagement and implementation of exercise in end-stage kidney disease: future theory-based interventions using the behavior change wheel. Semin Dial. 2019; 32:308-19.

19 Zelle DM, Klaassen G, Van Adrichem E, Bakker SJ, Corpeleijn E, Navis G. Physical inactivity: a risk factor and target for intervention in renal care. Nat Rev Nephrol. 2017;13(3):152.

20 Baggetta R, D’Arrigo G, Torino C, ElHafeez SA, Manfredini F, Mallamaci F, et al. Effect of a home based, low intensity, physical exercise program in older adult dialysis patients: a secondary analysis of the EXCITE trial. BMC Geriatr. 2018;18(1):248.

21 Hiraki K, Shibagaki Y, Izawa KP, Hotta C, Wakamiya A, Sakurada T, et al. Effects of home-based exercise on predialysis chronic kidney disease patients: a randomized pilot and feasibility trial. BMC Nephrol. 2017;18: 198.

22 Thomas RJ, Beatty AL, Beckie TM, Brewer LC, Brown TM, Forman DE, et al. Homebased cardiac rehabilitation: a scientific statement from the American Association of Cardiovascular and Pulmonary Rehabilitation, the American Heart Association, and the American College of Cardiology. Circulation. 2019 Jul 2;140(1):e69-89.

23 Whittaker F, Wade V. The costs and benefits of technology-enabled, home-based cardiac rehabilitation measured in a randomised controlled trial. J Telemed Telecare. 2014;20(7): 419-22.

24 Kraal JJ, Van den Akker-Van Marle ME, AbuHanna A, Stut W, Peek N, Kemps HM. Clinical and cost-effectiveness of home-based car- diac rehabilitation compared to conventional, centre-based cardiac rehabilitation: results of the FIT@Home study. Eur J Prev Cardiol. 2017 Aug;24(12):1260-73.

25 Chan KN, Chen Y, Lit Y, Massaband P, Kiratli J, Rabkin $\mathrm{R}$, et al. A randomized controlled trial of exercise to prevent muscle mass and functional loss in elderly hemodialysis patients: rationale, study design, and baseline sample. Contemp Clin Trials Commun. 2019; 15:100365.

26 de Souza e Silva CG, Kaminsky LA, Arena R, Christle JW, Araújo CGS, Lima RM, et al. A reference equation for maximal aerobic power for treadmill and cycle ergometer exercise testing: analysis from the FRIEND registry. Eur J Prev Cardiolog. 2018;25(7):742-50.

27 Myers J, Buchanan N, Walsh D, Kraemer M, McAuley P, Hamilton-Wessler M, et al. Comparison of the ramp versus standard exercise protocols. J Am Coll Cardiol. 1991;17(6): 1334-42.

28 Borg G. Borg's perceived exertion scales. Champaign: Human Kinetics Publishers; 1998.

29 American College of Sports Medicine. Guidelines for exercise testing and prescription. 10th ed. Baltimore: Lippincott, Williams, \& Wilkins; 2018.

30 Myers J, Goldsmith R, Keyteyian S, Brawner C, Ehrman JK, Brazil D, et al. The ventilatory anaerobic threshold in heart failure: a multicenter evaluation of reliability. J Card Fail. 2010;16:76-83.

31 Arena R, Myers J, Aslam SS, Varughese EB, Peberdy MA. Technical considerations related to the minute ventilation/carbon dioxide output slope in patients with heart failure. Chest. 2003;124(2):720-7.

32 Wasserman K, Stringer WW, Sun XG, Sue DY, Hansen JE, Whipp BJ, et al. Principals of exercise testing and interpretation. 5th ed. Baltimore: Lippincott, Williams \& Wilkins; 2011.

33 Klein DA, Katz DH, Beussink-Nelson L, Sanchez CL, Strzelczyk TA, Shah SJ. Association of chronic kidney disease with chronotropic incompetence in heart failure with preserved ejection fraction. Am J Cardiol. 2015;116(7): 1093-100.

34 Brazier JE, Harper NM, Jones A, O'Cathain KJ, Thomas T, Usherwood T, et al. Validating the SF-36 health questionnaire: a new outcome measure for primary care. BMJ. 1992; 305:160.

35 Rand Health Care. Kidney disease quality of life instrument [KDQOL]. Available from: https: //www.rand.org/health-care/surveys_ tools/kdqol.html. Accessed 2020 Jul 25.

36 Kurella M, Chertow GM, Luan J, Yaffe K. Cognitive impairment in chronic kidney disease. J Am Geriatr Soc. 2004;52(11):1863-9.

37 ATS. ATS statement: guidelines for the sixminute walk test. Am J Respir Crit Care Med. 2002;166(1):111-7.

38 Jones SE, Kon SS, Canavan JL, Patel MS, Clark AL, Nolan CM, et al. The five-repetition sit- to-stand test as a functional outcome measure in COPD. Thorax. 2013;68(11):1015-20.

39 Lobelo F, Rohm Young D, Sallis R, Garber MD, Billinger SA, Duperly J, et al. Routine assessment and promotion of physical activity in healthcare settings: a scientific statement from the American Heart Association. Circulation. 2018 May 1;137(18):e495-522.

40 Myers J, McAuley P, Lavie CJ, Despres JP, Arena R, Kokkinos P. Physical activity and cardiorespiratory fitness as major markers of cardiovascular risk: their independent and interwoven importance to health status. Prog Cardiovasc Dis. 2015;57(4):306-14.

41 Booth FW, Roberts CK, Thyfault JP, Ruegsegger GN, Toedebusch RG. Role of inactivity in chronic diseases: evolutionary insight and pathophysiological mechanisms. Physiol Rev. 2017;97(4):1351-402.

42 US health and human services physical activity guidelines for Americans. Available from: https: //health.gov/sites/default/files/2019--10/ CommitteeReport_7.pdf. Accessed 2020 Jul 15.

43 Delgado C, Johansen KL. Barriers to exercise participation among dialysis patients. Nephrol Dial Transplant. 2012;27(3):1152-7.

44 Salhab N, Karavetian M, Kooman J, Fiaccadori E, El Khoury CF. Effects of intradialytic aerobic exercise on hemodialysis patients: a systematic review and meta-analysis. J Nephrol. 2019 Aug;32(4):549-66.

45 QiuZ, Zheng K, Zhang H, Feng J, Wang L, Zhou $\mathrm{H}$. Physical exercise and patients with chronic renal failure: a meta-analysis. Biomed Res Int. 2017;2017:7191826.

46 Greenwood SA, Castle E, Lindup H, Mayes J, Waite I, Grant D, et al. Mortality and morbidity following exercise-based renal rehabilitation in patients with chronic kidney disease: the effect of programme completion and change in exercise capacity. Nephrol Dial Transplant. 2019;34(4):618-25.

47 Tikkanen-Dolenc H, Wadén J, Forsblom C, Harjutsalo V, Thorn LM, Saraheimo M, et al. Physical activity reduces risk of premature mortality in patients with type 1 diabetes with and without kidney disease. Diabetes Care. 2017;40(12):1727-32.

48 Sietsema KE, Amato A, Adler SG, Brass EP. Exercise capacity as a predictor of survival among ambulatory patients with end-stage renal disease. Kidney Int. 2004;65(2):719-24.

49 Torino C, Manfredini F, Bolignano D, Aucella $\mathrm{F}$, Baggetta R, Barillà $\mathrm{A}$, et al. Physical performance and clinical outcomes in dialysis patients: a secondary analysis of the EXCITE trial. Kidney Blood Press Res. 2014;39(2-3): 205-11.

50 Beddhu S, Baird BC, Zitterkoph J, Neilson J, Greene T. Physical activity and mortality in chronic kidney disease (NHANES III). Clin J Am Soc Nephrol. 2009;4(12):1901-6.

51 Kokkinos P, Faselis C, Myers J, Sui X, Zhang J, Tsimploulis A, et al. Exercise capacity and risk of chronic kidney disease in US veterans: a cohort study. Mayo Clin Proc. 2015;90(4): 461-8. 
52 Cheema BS, Chan D, Fahey P, Atlantis E. Effect of progressive resistance training on measures of skeletal muscle hypertrophy, muscular strength and health-related quality of life in patients with chronic kidney disease: a systematic review and meta-analysis. Sports Med. 2014;44(8):1125-38.

53 Sah SK, Siddiqui MA, Darain H. Effect of progressive resistive exercise training in improving mobility and functional ability of middle adulthood patients with chronic kidney disease. Saudi J Kidney Dis Transpl. 2015;26(5): 912-23.

54 Bae YH, Lee SM, Jo JI. Aerobic training during hemodialysis improves body composition, muscle function, physical performance, and quality of life in chronic kidney disease patients. J Phys Ther Sci. 2015;27(5):1445-9.

55 Thiebaud RS, Funk MD, Abe T. Home-based resistance training for older adults: a systematic review. Geriatr Gerontol Int. 2014;14: 750-7.

56 Pei G, Tang Y, Tan L, Tan J, Ge L, Qin W. Aerobic exercise in adults with chronic kidney disease [CKD]: a meta-analysis. Int Urol Nephrol. 2019;51:1787-95.

57 Myers J, Chan K, Chen Y, Lit Y, Massaband P, Tan J, et al. Association of physical function and performance with peak $\mathrm{VO} 2$ in end stage kidney disease. 2020, Submitted.

58 de Souza Faria R, Fernandes N, Moraes Lovisi JC, de Moura Reboredo M, de Moura Marta MS, do Valle Pinheiro B, et al. Pulmonary function and exercise tolerance are related to disease severity in pre-dialytic patients with chronic kidney disease: a crosssectional study. BMC Nephrol. 2013;14:184.

59 de Olival Fernandes A, Alves dos Santos Sens Y, Bertoni Xavier V, Antonio Miorin L, dos Santos Alves VL. Functional and respiratory capacity of patients with chronic kidney disease undergoing cycle ergometer training during hemodialysis sessions: a randomized clinical trial. Int J Nephrol. 2019;2019: 7857824 .
60 MacNee W. Aging, inflammation, and emphysema. Am J Respir Crit Care Med. 2011; 184(12):1327-9.

61 Tuder RM, Kern JA, Miller YE. Senescence in chronic obstructive pulmonary disease. Proc Am Thorac Soc. 2012;9(2):62-3.

62 Yuenyongchaiwat K, Namdang P, Vasinsarunkul $\mathrm{P}$, Phongsukree $\mathrm{P}$, Chaturattanachaiyaporn K, Pairojkittrakul S, et al. Effectiveness of inspiratory muscle training on respiratory fitness and breathlessness in chronic renal failure: a randomized control trial. Physiother Res Int. 2021 Jan;26(1):e1879.

63 de Lima MC, Cicotoste CL, Cardoso KS, Forgiarini LA, Monteiro MB, Dias AS. Effect of exercise performed during hemodialysis: strength versus aerobic. Ren Fail. 2013;35(5): 697-704.

64 Medeiros AIC, Brandão DC, Souza RJP, Fuzari HKB, Barros CESR, Barbosa JBN, et al. Effects of daily inspiratory muscle training on respiratory muscle strength and chest wall regional volumes in haemodialysis patients: a randomised clinical trial. Disabil Rehabil. 2019;41(26):3173-80.

65 Pomidori L, Lamberti N, Malagoni AM, Manfredini F, Pozzato E, Felisatti M, et al. Respiratory muscle impairment in dialysis patients: can minimal dose of exercise limit the damage? A preliminary study in a sample of patients enrolled in the EXCITE trial. J Nephrol. 2016;29(6):863-9.

66 Klein DA, Katz DH, Beussink-Nelson L, Sanchez CL, Strzelczyk TA, Shah SJ. Association of chronic kidney disease with chronotropic incompetence in heart failure with preserved ejection fraction. Am J Cardiol. 2015;116(7): 1093-100

67 Robinson TG, Carr SJ. Cardiovascular autonomic dysfunction in uremia. Kidney Int. 2002 Dec;62(6):1921-32.

68 Brubaker PH, Kitzman DW. Chronotropic incompetence: causes, consequences, and management. Circulation. 2011;123(9):101020.
69 Shetler K, Marcus R, Vora S, Kalisetti D, Prakash M, Do D, et al. Heart rate recovery: validation and methodological issues. J Amer Coll Cardiol. 2001;38:1980-7.

70 Manns B, Hemmelgarn B, Lillie E, Dip SC, Cyr A, Gladish M, et al. Setting research priorities for patients on or nearing dialysis. Clin J Am Soc Nephrol. 2014;9(10):1813-21.

71 Evangelidis N, Tong A, Manns B, Hemmelgarn B, Wheeler DC, Tugwell P, et al. Developing a set of core outcomes for trials in hemodialysis: an International Delphi Survey. Am J Kidney Dis. 2017;70(4):464-75.

72 Heiwe S, Jacobson SH. Exercise training for adults with chronic kidney disease. Cochrane Database Syst Rev. 2011;10(10):CD003236.

73 Manfredini F, Mallamaci F, D’Arrigo G, Baggetta R, Bolignano D, Torino C, et al. Exercise in patients on dialysis: a multicenter, randomized clinical trial. J Am Soc Nephrol. 2017 Apr;28(4):1259-68

74 Bossola M, Antocicco M, Di Stasio E, Ciciarelli C, Luciani G, Tazza L, et al. Mini Mental State Examination over time in chronic hemodialysis patients. J Psychosom Res. 2011; 71(1):50-4.

75 Buchman AS, Tanne D, Boyle PA, Shah RC, Leurgans SE, Bennett DA. Kidney function is associated with the rate of cognitive decline in the elderly. Neurology. 2009;73(12):920-7.

76 Bronas UG, Puzantian H, Hannan M. Cognitive impairment in chronic kidney disease: vascular milieu and the potential therapeutic role of exercise. Biomed Res Int. 2017;2017: 2726369.

77 Chu NM, McAdams-DeMarco MA. Exercise and cognitive function in patients with endstage kidney disease. Semin Dial. 2019;32(4): 283-90.

78 Fang HY, Burrows BT, King AC, Wilund KR. A comparison of intradialytic versus out-ofclinic exercise training programs for hemodialysis patients. Blood Purif. 2020;49(1-2): $151-7$. 